\title{
INTERPRETIVE SUMMARIES, JANUARY 2014
}

Do farm audits improve milk quality? By FloreMiyamoto et al., page 1. In this study, we showed that a farm audit has a decreasing effect on the total bacterial count in bulk milk for at least 6 mo. We analyzed a data set consisting of 13,007 audits performed on 12,855 Dutch dairy farms from February 2006 to April 2008, merged with 325,150 laboratory test results of bulk milk samples from 6 mo before and after the audit. The results show that average total bacterial counts decreased (2 to 6\%) from 1.5 mo after the audit to at least 6 mo after the audit.

http://dx.doi.org/10.3168/jds.2012-6228.

From goat colostrum to milk: Physical, chemical, and immune evolution from partum to $\mathbf{9 0}$ days postpartum. By Sánchez-Macías et al., page 10. Deciding when goat mammary secretion is colostrum, transitional milk, or milk is important for milk producers and goat keepers. Secretion composition, physical properties, and immunological parameters change throughout lactation; however, it is not clear when goat colostrum becomes milk. In this work, colostrum and milk characteristics were studied during the 90 days after birth, which will help to decide the best or most suitable use - kid rearing or pouring into the bulk milk tank for dairy processing.

http://dx.doi.org/10.3168/jds.2013-6811.

Prediction of fatty acid profiles in cow, ewe, and goat milk by mid-infrared spectrometry. By Ferrand-Calmels et al., page 1\%. The dairy industry needs tools to accurately predict the composition of milk. Mid-infrared spectrometry (MIR) appears to be a relevant, fast, and inexpensive method for assessing milk fatty acid profiles. This paper presents equations developed by French research teams to determine fatty acid profiles in cow, ewe, and goat milk using MIR spectra. This is the first report on such equations for ewe and goat milk. We conclude that MIR is a useful tool for large-scale fatty acid prediction in milk.

http://dx.doi.org/10.3168/jds.2013-6648.

Combined effect of active coating and modified atmosphere packaging in prolonging the shelf life of low-moisture Mozzarella cheese. By Mastromatteo et al., page 36. This study was conducted to evaluate the effect of active coating and modified atmosphere packaging on low-moisture Mozzarella cheese stored at 4,8 , and $14^{\circ} \mathrm{C}$. The approach used was effectively able to prolong the shelf life of the product by inhibiting spoilage microorganisms and molds. Moreover, this strategy enhanced the safety of the product under thermal abuse conditions. The simplicity and relative economy of the edible coatings could be very beneficial and of commercial importance to the dairy industry. http://dx.doi.org/10.3168/jds.2013-6999.

Microbiological safety and quality of Mozzarella cheese assessed by the microbiological survey method. By Losito et al., page 46. The paper describes the validation of the microbiological survey (MBS) method for the selective count of lactic acid bacteria and its use to assess the microbiological safety and quality of Mozzarella cheese. The MBS method can be used by small- to medium-sized cheese factories not having an internal microbiological laboratory to monitor the microbiological quality and safety of the production process and final products.

http://dx.doi.org/10.3168/jds.2013-7026.

Performance assessment of membrane distillation for skim milk and whey processing. $B y$ Hausmann et al., page 56. This study investigated a new separation process for the dairy industry, membrane distillation (MD), for concentrating skim milk or whey. Membrane distillation may replace reverse osmosis (RO) as a low-energy concentration operation; therefore, a study was undertaken to assess its potential compared with RO in terms of performance. Under certain operating conditions, $\mathrm{MD}$ can perform equally to $\mathrm{RO}$ and thus can concentrate skim milk or whey before drying to at least $20 \%$ solids without high pressure and without the high electricity demand of RO.

http://dx.doi.org/10.3168/jds.2013-7044.

Usage of sodium polyphosphates with different linear lengths in the production of spreadable processed cheese. By Nagyová et al., page 111. The paper contributes to the understanding of function of phosphate emulsifying salts in processed cheese production. We describe the effect of sodium salts of polyphosphate with different mean lengths in ternary mixtures with sodium monophosphate, diphosphate, or triphosphate on textural parameters of processed cheese spreads. These results could be applied when designing emulsifying salt composition for processed cheeses with appropriate properties. Processed cheese consistency was also affected by $\mathrm{pH}$.

http://dx.doi.org/10.3168/jds.2013-7210.

Recovery of n-3 polyunsaturated fatty acids and conjugated linoleic acids in ripened cheese obtained from milk of cows fed different levels of extruded flaxseed. By Cattani et al., page 123. Two levels (500 or 1,000 g/d per head) of extruded flaxseed were supplemented to dairy cows to explore possible 
effects on milk fatty acid content and recovery in ripened cheese $(90 \mathrm{~d})$. The addition of flaxseed to the diet did not influence average fat recovery (approximately 0.85), irrespective of flaxseed level, although some differences were found in the recovery of single fatty acids. Furthermore, supplementation of $500 \mathrm{~g} / \mathrm{d}$ per head of extruded flaxseed was sufficient to improve the fatty acid profile of milk and ripened cheese through a notable increment in the proportion of n-3 fatty acids. http://dx.doi.org/10.3168/jds.2013-7213.

Osteopontin is highly susceptible to cleavage in bovine milk and the proteolytic fragments bind the $\alpha_{\mathrm{V}} \boldsymbol{\beta}_{3}$-integrin receptor. By Christensen and Sørensen, page 136. Osteopontin (OPN) is an immunostimulatory protein present in milk in relatively high concentrations. Proteolytic cleavage of OPN controls its ability to interact with cells through integrin receptors. In this study, we characterized several fragments of OPN in bovine milk cleaved close to its integrin binding motif. Osteopontin was especially susceptible to cleavage at the Phe151-Arg152 peptide bond, and the cleaved protein could proficiently interact with cells via the $\alpha_{V} \beta_{3}$-integrin. Thus, OPN in bovine milk is able to interact with cellular integrin receptors in milk and in the gastrointestinal tract.

http://dx.doi.org/10.3168/jds.2013-7223.

Epilactose production by two cellobiose 2-epimerases in original milk. By Krewinkel et al., page 155. The mesophilic cellobiose 2-epimerases from Flavobacterium johnsoniae and Pedobacter heparinus were utilized in milk to produce the prebiotic sugar epilactose in situ. The enzymatic bioconversion was carried out at a low temperature $\left(8^{\circ} \mathrm{C}\right)$ relevant to industrial processes typically used in the dairy industry. No substances other than the enzymes had to be added and, because of the reaction specificity of the cellobiose 2 -epimerases, no side products were generated. The method described is a possible novel process to gain milk products with added value in the future.

http://dx.doi.org/10.3168/jds.2013-7389.

Short communication: Effect of active food packaging materials on fluid milk quality and shelf life. By Wong and Goddard, page 166. Lactase was covalently immobilized onto low-density polyethylene using polyethyleneimine and glutaraldehyde crosslinkers to form a bioactive packaging film. Because of the potential contaminants of proteases, lipases, and spoilage organisms in typical enzyme preparations, the goal of the current work was to determine the effect of immobilized-lactase active packaging technology on unanticipated side effects such as shortened shelf life and reduced product quality.

http://dx.doi.org/10.3168/jds.2013-7214.
Prevalence of and factors associated with hock, knee, and neck injuries on dairy cows in freestall housing in Canada. By Zaffino Heyerhoff et al., page 173. This study determined the prevalence of, and identified factors associated with, injuries of dairy cattle on freestall farms in Ontario and Alberta, Canada. Overall, $47 \%$ of cows were injured. Increasing parity was associated with knee and neck injuries. Lameness was associated with greater odds of hock injury, whereas a sand stall base was a protective factor for hock injury. The odds of knee injury were greater on farms where cows slipped or fell and were lower on farms with rubber flooring in front of the feed bunk compared with concrete. Low feed-rail heights increased the odds of neck injury.

http://dx.doi.org/10.3168/jds.2012-6367.

Effect of an Ovsynch56 protocol initiated at different intervals after insemination with or without a presynchronizing injection of gonadotropin-releasing hormone on fertility in lactating dairy cows. By Bruno et al., page 185. Resynchronization protocols are widely used to reduce the interval between artificial insemination in nonpregnant dairy cows. Percentages of cows pregnant to reinsemination were not altered by type of resynchronization protocol. Protocols using a presynchronizing gonadotropinreleasing hormone, however, decreased the percentage of cows inseminated on detected estrus and increased the percentage of cows inseminated at a fixed time. Cows inseminated on detected estrus had greater pregnancy per artifical insemination than cows inseminated at fixed time.

http://dx.doi.org/10.3168/jds.2013-6827.

Endometrial cytology, biopsy, and bacteriology for the diagnosis of subclinical endometritis in grazing dairy cows. By Madoz et al., page 195. The objectives of this study were to assess the agreement between endometrial cytology and uterine biopsy for the diagnosis of subclinical endometritis (SEND) in grazing dairy cows, and to describe the bacterial population isolated from the uterus of cows having subclinical endometritis. We observed little agreement between cytology and biopsy outputs such that biopsy would not be useful in the diagnosis of SEND. The likelihood of having a normal biopsy was greater for healthy cows than for those having SEND. Finally, no bacteria were isolated from cows with SEND.

http://dx.doi.org/10.3168/jds.2013-6836.

Factors influencing dairy calf and replacement heifer mortality in France. By Raboisson et al., page 202. Calf and heifer mortality represent high economic losses and is also a welfare issue. France is a suitable example for identifying the combination of factors as- 
sociated with high or low mortality because of its broad diversity of livestock systems. In the present study, new herd-level factors influencing dairy calf and heifer mortality were identified. The know-how in young calf management gained from the presence of a beef herd within the farm facilitates the reduction in mortality of dairy calves. Dairy heifer mortality decreases when the availability of replacement heifers is low. These determinants of dairy calf and heifer mortality are important for farmer advisors and the dairy industry.

http://dx.doi.org/10.3168/jds.2013-6847.

Preoperative cow-side lactatemia measurement predicts negative outcome in Holstein dairy cattle with right abomasal disorders. By Boulay et al., page 212. The usefulness of preoperative L-lactate concentration, in addition to heart rate measurement, as a predictor of negative outcome for right displaced abomasum or abomasal volvulus in dairy cattle was evaluated. L-Lactate concentration was found to be a valuable prognostic indicator and the combination with heart rate improved prognosis accuracy compared with heart rate alone. We identified L-lactate thresholds that would indicate the benefit of surgical treatment versus culling of animal.

http://dx.doi.org/10.3168/jds.2013-6898.

Serum iron as an indicator of acute inflammation in cattle. By Baydar and Dabak, page 222. The present investigation was undertaken to assess the value of serum iron concentration in the diagnosis of acute inflammation in cattle. The diagnostic value of this approach was compared with that of the hematological tests and acute phase proteins used currently. The results of this study indicate that serum iron analysis, preferably in combination with other markers of inflammation, may be a useful diagnostic tool for acute inflammation in cattle. Because serum iron measurement is individually available and easily applicable, it may be used for clinical cases as well as for determination of herd health. http://dx.doi.org/10.3168/jds.2013-6939.

Consequences of transfer of an in vitro-produced embryo for the dam and resultant calf. By Bonilla et al., page 229. Calves were produced by transfer of in vitro-produced embryos (ET) or artificial insemination (AI). There was little consequence of gestating a calf produced by ET for the dam. However, birth weight was more variable for ET calves than for AI calves, and the incidence of death losses was greater for ET calves. Milk yield during the first lactation was similar for ET and AI calves. Characteristics of the resulting calves should be a consideration when optimizinge culture conditions for production of calves by ET.

http://dx.doi.org/10.3168/jds.2013-6943.
Distribution and identification of culturable airborne microorganisms in a Swiss milk processing facility. By Brandl et al., page 240. Airborne particle concentration measurements combined with enumeration and characterization of total culturable airborne bacteria were performed within a milk powder processing facility. Numbers of microorganisms were generally very low ( $<100 \mathrm{cfu} / \mathrm{m}^{3}$ of air) during milk powder production. Airborne particles in the size range of 1 to $5 \mu \mathrm{m}$ were highly correlated with the microbiological counts observed. This observation might form the foundation for a surveillance system based upon airborne particle counting. Data will help to evaluate the effectiveness of the milk powder processing facility's sanitation program and to identify sources of airborne contamination, resulting in increased food safety.

http://dx.doi.org/10.3168/jds.2013-7028.

Microarray-based gene expression profiling of peripheral blood mononuclear cells in dairy cows with experimental hypocalcemia and milk fever. By Sasaki et al., page 24\%. Peripheral blood mononuclear cells from cows with experimentally induced hypocalcemia or spontaneous milk fever were subjected to oligo-microarray analysis to identify specific biomarker genes. In experimental hypocalcemia, 32 genes were significantly up- or downregulated compared with the control treatment. In cows with milk fever, 98 genes were expressed differentially (either up- or downregulated) compared with healthy parturient cows. From these data, 5 genes were selected as being strongly related to both experimental hypocalcemia and milk fever. Another gene was also determined to be specific for milk fever independently of hypocalcemia.

http://dx.doi.org/10.3168/jds.2013-7049.

Analysis of milking characteristics in New Zealand dairy cows. By Edwards et al., page 259. The milking duration of individual cows is an important factor in determining herd milking duration. In this study, we quantified the phenotypic variation and genetic correlations in the milking characteristics of grazing cows and discussed the possible physiological basis of these differences. Residual milking duration can be used to identify and select efficient milking animals. Useful data for operators wishing to apply a maximum milking time strategy are provided.

http://dx.doi.org/10.3168/jds.2013-7051.

Evaluation of selective dry cow treatment following on-farm culture: Risk of postcalving intramammary infection and clinical mastitis in the subsequent lactation. By Cameron et al., page 270. A Petrifilm-based on-farm milk culture system was used to select cows for intramammary antimicrobial 
treatment at the end of lactation. When the risk of postcalving intramammary infection and clinical mastitis in the subsequent lactation was compared between cows receiving Petrifilm-based selective antimicrobial treatment and cows receiving total antimicrobial treatment, no significant differences were observed. In contrast to the widespread practice of total antimicrobial treatment of cows at the end of lactation, using a Petrifilm on-farm milk culture system to select cows for antimicrobial treatment can reduce the quantity of antimicrobials used in dairy production.

http://dx.doi.org/10.3168/jds.2013-7060.

Molecular epidemiology of recurrent clinical mastitis due to Streptococcus uberis: Evidence of both an environmental source and of recurring infection with the same strain. By Abureema et al., page 285. Most recurrences of clinical mastitis due to Streptococcus uberis were caused by a new strain, indicating that treatment of the initial infection with intramammary cloxacillin was usually successful. A small number of recurrences were caused by the initial strain in the same quarter, indicating persistence, or in a new quarter, indicating either spread between quarters or reactivation of a previous subclinical infection. No strain-specific propensity to cause persistent infection was detected.

http://dx.doi.org/10.3168/jds.2013-7074.

Effects of time and sampling location on concentrations of $\beta$-hydroxybutyric acid in dairy cows. By Mahrt et al., page 291. Blood concentration of $\beta$-hydroxybutyric acid (BHBA) plays an important role in the diagnosis of subclinical ketosis in dairy cows. Previous studies found diurnal patterns and effects of sampling time on blood BHBA concentration, which were associated with feeding strategies. Sampling time had no effect on BHBA concentration in continuously fed dairy cows in our study. In a second experiment, effects of blood sampling location on BHBA concentration were studied. Samples for measurement of BHBA should be collected from the jugular vein or tail vessels. http://dx.doi.org/10.3168/jds.2013-7099.

Evaluation of milk ELISA for detection of $M y$ cobacterium avium subspecies paratuberculosis in dairy herds and association with within-herd prevalence. By Lavers et al., page 299. Cow-level milk ELISA results were used to determine herd-level Mycobacterium avium ssp. paratuberculosis (MAP) status. Milk sample collection is minimally invasive, and ELISA results can be obtained quickly and economically. This study evaluated herd-level test characteristics of milk ELISA in 32 dairy herds over a 2-yr interval. Six of the 14 MAP-positive herds had a mean fecal culture within-herd prevalence $\leq 5 \%$. Although milk ELISA was an acceptable method of determining herd MAP status in high-prevalence herds, in low-prevalence and MAP-negative herds, false-negative and false-positive herd test results, respectively, were frequent.

http://dx.doi.org/10.3168/jds.2013-7101.

Prevalence and risk factors for udder cleft dermatitis in dairy cows. By Persson Waller et al., page 310. Udder cleft dermatitis (UCD) is a skin lesion located between the udder and the abdominal wall or between the front quarters. The prevalence of UCD and its risk factors were studied in 30 herds in one county of Sweden. Varying degrees of UCD were found in almost one-fifth of the cows. The within-herd cow prevalence varied between 0 and 39\% (average 18.5\%). Risk factors were breed, parity, production level, and veterinary-treated clinical mastitis. A strong udder attachment was a protective factor. The primary cause of UCD is still unclear and more knowledge is needed to prevent this animal welfare problem.

http://dx.doi.org/10.3168/jds.2013-7186.

Climatic effects on milk production traits and somatic cell score in lactating Holstein-Friesian cows in different housing systems. By Lambertz et al., page 319. Global warming will probably intensify heat stress for dairy cows. It is unknown to what extent different housing systems can alter this stress. Therefore, the effect of the temperature-humidity index as an indicator of heat stress on milk production traits was studied in 4 housing systems in Germany. Negative effects of heat stress on the studied traits were observed. However, a housing system superior to other systems in altering heat-stress effects was not identified.

http://dx.doi.org/10.3168/jds.2013-7217.

Induced hyperketonemia affects the mammary immune response during lipopolysaccharide challenge in dairy cows. By Zarrin et al., page 330. Effects of an induced hyperketonemia through $\beta$-hydroxybutyrate (BHBA) infusion and an additional intramammary lipopolysaccharide (LPS) challenge on immune response in liver and mammary gland were studied in mid-lactating dairy cows. Infusion of BHBA caused increased acute phase protein messenger (m) RNA abundance in the mammary gland but not in the liver. The LPS-related increase of somatic cell count was less pronounced, whereas mRNA abundance of interleukin- 8 and interleukin-10 increased more in the response to LPS in the group receiving BHBA infusion than in the control animals. The results demonstrate that elevated BHBA most likely has a direct effect on the susceptibility of mastitis.

http://dx.doi.org/10.3168/jds.2013-7222.

Short communication: Antimicrobial resistance and virulence characterization of methicillinresistant staphylococci isolates from bovine 
mastitis cases in Portugal. By Seixas et al., page 340. Methicillin-resistant staphylococci (MRS) have already been reported as mastitis agents. Such bacterial species are a public health concern, because the presence of these bacteria requires antimicrobial therapy of bovine mastitis and can be transferred to humans. This work evaluated the MRS distribution among 204 staphylococci from bovine mastitis. We evaluated resistance against several classes of antimicrobial agents, characterized the virulence profile of the MRS isolates, and assessed biofilm production, because biofilms can complicate infection or decrease antimicrobial therapeutics efficacy. Our results indicate that MRS frequently express virulence traits that can represent a serious challenge to clinicians.

http://dx.doi.org/10.3168/jds.2013-7130.

Short communication: The pharmacological peroxisome proliferator-activated receptor $\alpha$ agonist WY-14,643 increases expression of novel organic cation transporter 2 and carnitine uptake in bovine kidney cells. By Zhou et al., page 345. In rodents, expression of the carnitine transporter novel organic cation transporter 2 (OCTN2) is regulated by peroxisome proliferator-activated receptor $\alpha$ (PPAR $\alpha$ ), a central regulator of energy homeostasis. Less is known about the regulation of OCTN2 by PPAR $\alpha$ and its role for carnitine transport in cattle, even though PPAR $\alpha$ activation physiologically occurs in the liver of high-producing cows during early lactation. The present study shows that expression of the carnitine transporter OCTN2 and OCTN2-mediated carnitine uptake are also regulated by PPAR $\alpha$ in bovine cells. The observed PPAR $\alpha$ dependence of OCTN2 expression provides a plausible explanation for the recent finding that OCTN2 in the liver is strongly upregulated during early lactation in high-producing dairy cows. http://dx.doi.org/10.3168/jds.2013-7161.

Technical note: A comparison of 2 methods of assessing lameness prevalence in tiestall herds. By Gibbons et al., page 350. We described a method of assessing lameness in cows held in tiestalls that does not require that cows be moved from their stalls, has good intra- and interobserver reliability, and gives a similar estimate of herd prevalence as gait scoring.

http://dx.doi.org/10.368/jds.2013-6783.

Evaluation of predictions of volatile fatty acid production rates by the Molly cow model. By Ghimire et al., page 354. Data on rates of bovine volatile fatty acid production from several publications were used to evaluate the accuracy and precision of predictions by the Molly cow model. The results indicated that the model poorly predicted net volatile fatty acid production rates. Further work indicated that lack of consideration of interconversions among volatile fatty acids may be contributing to the errors of prediction. Thus, consideration of interconversions driven by thermodynamics may improve predictions of net volatile fatty acid production rates.

http://dx.doi.org/10.3168/jds.2012-6199.

Comparative efficacy of enrofloxacin and tulathromycin for treatment of preweaning respiratory disease in dairy heifers. By Heins et al., page 372. The objective was to determine the efficacy of treatment of preweaned respiratory disease in dairy heifers with enrofloxacin or tulathromycin and the subsequent effect of disease and treatment on average daily gain in the preweaned period. Calves treated with tulathromycin experience fewer retreatments than calves treated with enrofloxacin. We found no difference in average daily gain for calves treated with enrofloxacin or tulathromycin for respiratory disease and apparently healthy animals or between treatment groups. These results may be used to guide future treatment programs for replacement dairy animals.

http://dx.doi.org/10.3168/jds.2013-6696.

The effect of relocation of whole-crop wheat and corn silages on their quality. By Chen and Weinberg, page 406. Whole-crop wheat and corn silages in mini silos were exposed to air during their anaerobic storage period for 0 to $48 \mathrm{~h}$ to simulate moving of silages. When silages were of high quality and did not contain factors that might enhance their aerobic instability, duration of such exposure had only minor effects on their quality. However, when homofermentative lactic acid bacteria were used, exposing the silages during their storage period enhanced their aerobic deterioration in aerobic stability tests that simulate the feed-out phase.

http://dx.doi.org/10.3168/jds.2013-7098.

The effects of forage particle length and exogenous phytase inclusion on phosphorus digestion and absorption in lactating cows. By Jarrett et al., page 411. In situations where ruminal digestion of phytate (Pp) may be incomplete, slowing digesta passage or adding phytase could compensate. This experiment with ruminally and ileally cannulated lactating cows evaluated the effects of forage particle length and phytase supplementation on phosphorus $(\mathrm{P})$ digestion and absorption. With phytase addition, dietary Pp was rapidly degraded before intake and total-tract Pp digestion was increased. Phytase supplementation did not improve the efficiency of dietary P utilization, probably because late lactation cows were fed P-adequate diets. http://dx.doi.org/10.3168/jds.2013-7124.

Decline in mammary translational capacity during intravenous glucose infusion into lactating dairy cows. By Curtis et al., page 430. Glucose, an energy substrate, may stimulate milk protein yield in lac- 
tating dairy cattle. To test the effects of glucose on milk protein and the mechanism behind the response, cows were intravenously infused with glucose, and mammary biopsies were collected. Based on blood and mammary tissue results, we concluded that the mammalian target of rapamycin signaling pathway is not the only regulator of milk protein synthesis in the mammary glands. In addition, glucose stimulated protein synthesis in muscle rather than the mammary glands.

http://dx.doi.org/10.3168/jds.2013-7252.

Use of dietary feather meal to induce histidine deficiency or imbalance in dairy cows and effects on milk composition. By Stahel et al., page 439 Deficiency in the amino acid histidine decreases milk protein and increases milk fat content. Dietary feather meal, which is high in protein but low in histidine, was studied for its ability to alter milk composition by inducing histidine deficiency. Feather meal inclusion at $12.6 \%$ of the diet decreased plasma histidine, decreased milk protein and lactose yields, and increased milk fat content. Feather meal inclusion could be used to lower the solids-not-fat:fat ratio of milk, which is particularly important to producers who face penalties for exceeding a set ratio.

http://dx.doi.org/10.3168/jds.2013-7269.

Moist and dry heating-induced changes in protein molecular structure, protein subfractions, and nutrient profiles in camelina seeds. By Peng et al., page 446. This study aimed to reveal protein molecular structure changes induced by moist and dry heating $\left(120^{\circ} \mathrm{C}\right.$ for $\left.60 \mathrm{~min}\right)$ in relation to protein nutritive value and digestive behavior in the rumen and intestine of the dairy cattle. Compared with dry heating, moist heating markedly decreased protein solubility and rumen degradability and increased intestinal digestibility of rumen undegraded protein. These changes were associated with alteration of protein intrinsic molecular structures. Moist heating improved feed-protein utilization in dairy cattle.

http://dx.doi.org/10.3168/jds.2013-7298.

Genomic selection strategies in a small dairy cattle population evaluated for genetic gain and profit. By Thomasen et al., page 458. We have demonstrated that low reliabilities of genomic predictions set limitations for moving towards more genetically efficient breeding schemes with more intensive use of young bulls without progeny testing. Strong positive interaction effects between increased reliability of genomic predictions and more intensive use of young bulls exist. From an economic perspective, a juvenile scheme is always advantageous. The main future focus area for smaller dairy cattle breeds should be to join forces to increase reliabilities of genomic predictions.

http://dx.doi.org/10.3168/jds.2013-6599.
The effects of heat stress in Italian Holstein dairy cattle. By Bernabucci et al., page 471. Heat tolerance is currently considered one of the most important adaptive aspects in dairy cattle in temperate zones characterized by long and hot summers. The definitions of temperature-humidity index thresholds for productive traits and the inclusion of heat tolerance traits in models used for the estimation of genetic values will be useful in helping to select sires that are responsive to hot conditions.

http://dx.doi.org/10.3168/jds.2013-6611.

On the limited increase in validation reliability using high-density genotypes in genomic best linear unbiased prediction: Observations from Fleckvieh cattle. By Ertl et al., page 48\%. High-density genotypes provide refined information about the inheritance of quantitative trait loci. Reliability and inflation of genomic breeding values predicted with marker panels containing 40,089 and 388,951 single nucleotide polymorphisms were compared in the Fleckvieh breed. The advantage of high-density genotypes for validation reliability was small (0.015 and 0.028 depending on the type of comparison) but significant. Increased regression coefficients of phenotypes on predictions of 0.036 indicated reduced inflation. The model-based reliability decreased with higher marker density. The observed improvement of validation reliability and inflation is related to an improved estimation of the realized relationship matrix.

http://dx.doi.org/10.3168/jds.2013-6855.

Genetic evaluation of in-line recorded milkability from milking parlors and automatic milking systems. By Carlström et al., page 497. Technical advances in milking systems and equipment offer the possibility of in-line recording of milkability traits, such as milk flow rate and milking time, in commercial dairy herds. However, routine genetic evaluations for milkability traits based on automatically recorded data have not been implemented yet in Sweden. Medium to high heritabilities and high correlations between milking systems show the potential to combine data from automatic milking systems and conventional parlors for genetic evaluation.

http://dx.doi.org/10.3168/jds.2013-6948.

A study based on records taken at time of hoof trimming reveals a strong association between the IQ motif-containing GTPase-activating protein 1 (IQGAP1) gene and sole hemorrhage in Holstein cattle. By Swalve et al., page 50\%. Sole hemorrhage is regarded as an important disorder of the bovine hoof. Its etiology shows that the background of this disorder can be attributed mostly to environmental factors and especially to feeding. Aside from this, a genetic predisposition exists. In a planned experiment 
conducted in 7 large dairies and based on data from 1,962 first-lactation cows, the association between disorder status and single nucleotide polymorphisms (SNP) for 384 preselected SNP representing candidate genes was examined. One SNP, an intronic SNP of the IQGAP1 gene on Bos taurus autosome, showed a highly significant association with sole hemorrhage status. In the validation experiment, this association was also identified as significant in a sample of 2,394 bulls when considering breeding values for feet and leg conformation.

http://dx.doi.org/10.3168/jds.2013-6997.

Genetic and genomic dissection of dry matter intake at different lactation stages in primiparous Holstein cows. By Tetens et al., page 520. Feed is a major component of milk production costs and sufficient feed intake in early lactation is required to counteract pronounced negative energy balance. Lactation stage-specific selection might make it possible to optimize the trajectory of feed intake across lactation to meet these goals, but this requires more in-depth knowledge about genetic parameters. Within the current study, daily heritabilities for dry matter intake and genetic correlations between lactation stages were estimated, and sequential genome-wide association studies were conducted on 5 lactation days. The results contribute to our knowledge about the genetic architecture of dry matter intake and might assist future selection efforts.

http://dx.doi.org/10.3168/jds.2013-7301.

Short communication: Genetic characterization of digital cushion thickness. By Oikonomou et al., page 532. Digital cushion thickness is phenotypically associated with claw horn disruption lesions (sole ulcers and white line disease) and lameness. The objective of this study was to characterize digital cushion thickness genetically and to investigate its association with body condition score, locomotion score, claw horn disruption lesions, and milk production. Digital cushion thickness was found to be moderately heritable and was genetically negatively correlated with sole ulcer and white line disease.

http://dx.doi.org/10.3168/jds.2013-7212.

Short communication: Validation of genomic breeding value predictions for feed intake and feed efficiency traits. By Pryce et al., page 53\%. Published genomic prediction equations for dry matter intake and residual feed intake were validated in a population of 78 multiparous Australian Holsteins. For residual feed intake, the reference population was growing heifers, and the realized accuracy in the lactating cow population was $68 \%$ of the equivalent realized accuracy in growing heifers (0.4). Even greater accuracies were achieved when dry matter intake records from lactating cows from other countries were included in the reference population (with means of 0.26 to 0.72 ). Multi-country collaboration in the area of dairy cow feed efficiency is one pathway to achieving acceptable accuracies of genomic prediction for these valuable traits.

http://dx.doi.org/10.3168/jds.2013-7376.

Effect of Sicilian pasture feeding management on contents of $\alpha$-tocopherol and $\beta$-carotene in cow milk. By Marino et al., page 543. This study was performed to evaluate $\alpha$-tocopherol and $\beta$-carotene contents of pasture milk under ordinary Sicilian farming conditions. Higher $\alpha$-tocopherol and $\beta$-carotene levels were observed in milk from spontaneous compared with cultivated pasture. These results may be explained by the different botanical composition and pasture intake. The highest milk fat-soluble vitamin content was obtained when feeding spontaneous pasture at high levels in spring.

http://dx.doi.org/10.3168/jds.2013-7005.

Evaluation of effects of metritis management in a complex dairy herd health management program. By Krogh and Enevoldsen, page 552. Examination for metritis early postpartum was evaluated as part of a larger herd health management program in 121 herds over a 15-yr period. For parity group 1, the negative effects of metritis (with treatment) on 305-d milk production after a normal calving were reduced by $116 \mathrm{~kg}$ of energy-corrected milk after enrollment in the program. For parity groups 2 and $>2$, enrollment in the herd health management program resulted in increases in energy-corrected milk yield of 129 and 80 $\mathrm{kg}$, respectively. This effect appeared to be mediated through improved metritis detection.

http://dx.doi.org/10.3168/jds.2012-5580.

Accuracy and precision of total mixed rations fed on commercial dairy farms. By Sova et al., page 562. A cross-sectional study of 22 commercial dairy farms was conducted to describe deviations between the fed and formulated rations, evaluate daily variability in total mixed ration characteristics, and examine associations with measures of productivity. The results illustrate the importance of ensuring ration consistency to maximize dry matter intake, milk yield, and efficiency of milk production.

http://dx.doi.org/10.3168/jds.2013-6951. 